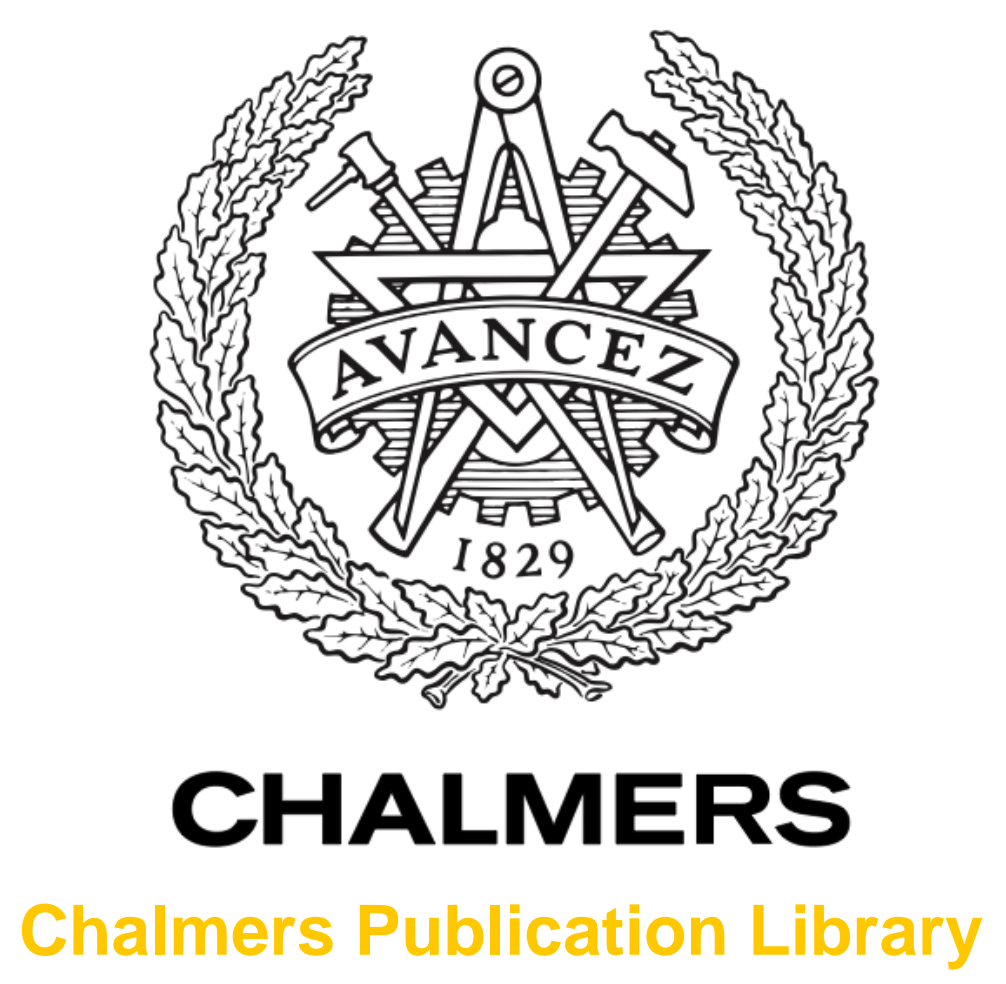

High-Speed VCSELs With Strong Confinement of Optical Fields and Carriers

This document has been downloaded from Chalmers Publication Library (CPL). It is the author's version of a work that was accepted for publication in:

Journal of Lightwave Technology (ISSN: 0733-8724)

Citation for the published paper:

Haglund, E. ; Westbergh, P. ; Gustavsson, J. et al. (2016) "High-Speed VCSELs With Strong Confinement of Optical Fields and Carriers". Journal of Lightwave Technology, vol. 34(2), pp. 269-277.

http://dx.doi.org/10.1109/jlt.2015.2458935

Downloaded from: http://publications.lib.chalmers.se/publication/233624

Notice: Changes introduced as a result of publishing processes such as copy-editing and formatting may not be reflected in this document. For a definitive version of this work, please refer to the published source. Please note that access to the published version might require a subscription.

Chalmers Publication Library (CPL) offers the possibility of retrieving research publications produced at Chalmers University of Technology. It covers all types of publications: articles, dissertations, licentiate theses, masters theses, conference papers, reports etc. Since 2006 it is the official tool for Chalmers official publication statistics. To ensure that Chalmers research results are disseminated as widely as possible, an Open Access Policy has been adopted.

The CPL service is administrated and maintained by Chalmers Library. 


\title{
High-Speed VCSELs with Strong Confinement of Optical Fields and Carriers
}

\author{
Erik Haglund, Student Member, IEEE, Petter Westbergh, Johan S. Gustavsson, \\ Emanuel P. Haglund, Student Member, IEEE, and Anders Larsson, Fellow, IEEE, Fellow, OSA
}

\begin{abstract}
We present the design, fabrication, and performance of our latest generation high-speed oxide-confined $850-\mathbf{n m}$ vertical-cavity surface-emitting lasers. Excellent high-speed properties are obtained by strong confinement of optical fields and carriers. High-speed modulation is facilitated by using the shortest possible cavity length of one half wavelength and placing oxide apertures close to the active region to efficiently confine charge carriers. The resulting strong current confinement boosts internal quantum efficiency, leading to low threshold currents, high wallplug efficiency, and state-of-the-art high-speed properties at low bias currents. The temperature dependent static and dynamic performance are analyzed by current-power-voltage and smallsignal modulation measurements.
\end{abstract}

Index Terms - Dynamics, high efficiency, high-speed modulation, optical interconnects, semiconductor lasers, verticalcavity surface-emitting lasers (VCSELs).

\section{INTRODUCTION}

$\mathrm{V}$ ERTICAL-cavity surface-emitting lasers (VCSELs) are extensively used in short-reach multimode fiber (MMF) optical interconnects in data centers and supercomputers. Today, a single supercomputer may use several million optical interconnects and near-future systems are expected to employ tens or hundreds of million interconnects operating at 25 to $50 \mathrm{Gbit} / \mathrm{s}[1,2]$. Further into the future, terabit optical interconnects may require even higher channel rates. As no active cooling can be used due to high power consumption and cost, future optical interconnects require VCSELs with excellent high-speed properties also at high temperatures.

The last few years have seen an impressive improvement in the performance of high-speed short-wavelength VCSELs emitting at 850-980-1060 nm. Current records for back-to-back transmission (a few meters of multimode fiber) are compiled in Table I. Our previous generation high-speed VCSELs could transmit error-free (bit-error-ratio $(\mathrm{BER})<10^{-12}$ ) at bit rates up to $57 \mathrm{Gbit} / \mathrm{s}$ using non-return-to-zero on-off keying [3]. By using equalization, the bit rate could be boosted to $71 \mathrm{Gbit} / \mathrm{s}$ at room temperature (RT) and $50 \mathrm{Gbit} / \mathrm{s}$ at $90^{\circ} \mathrm{C}[4,5]$. Without equalization, high bit-rate, high-temperature transmission at

Manuscript received May 30, 2015; revised July 10, 2015; accepted July 10 , 2015. Date of current version July 18, 2015.

E. Haglund, P. Westbergh, J. S. Gustavsson, E. P. Haglund, and A. Larsson are with the Department of Microtechnology and Nanoscience, Photonics Laboratory, Chalmers University of Technology, SE-412 96, Sweden (e-mail: erik.haglund@chalmers.se; petter.westbergh@chalmers.se;
TABLE I

SHORT-WAVELENGTH VCSELS FOR OPTICAL INTERCONNECTS

\begin{tabular}{|c|c|c|c|c|c|}
\hline Group & $\begin{array}{c}\lambda \\
(\mathrm{nm})\end{array}$ & $\begin{array}{l}\text { BW }(\mathrm{GHz}) / \\
\mathrm{BR}(\mathrm{Gbit} / \mathrm{s})\end{array}$ & $\begin{array}{c}\mathrm{T} \\
\left({ }^{\circ} \mathrm{C}\right)\end{array}$ & Energy eff. & Year [Ref.] \\
\hline \multicolumn{6}{|c|}{ High bandwidth } \\
\hline Chalmers $^{\mathrm{a}}$ & 850 & 30 & RT & & 2015 [11] \\
\hline UIUC $^{\mathrm{b}}$ & 980 & 37 & RT & & 2015 [7] \\
\hline TU Berlin & 980 & 23 & 85 & & $2014[6]$ \\
\hline \multicolumn{6}{|c|}{ High bit rate } \\
\hline Chalmers & 850 & 57 & RT & & 2013 [3] \\
\hline IBM-Chalmers $^{\mathrm{c}}$ & 850 & 71 & RT & & $2015[4]$ \\
\hline TU Berlin & 980 & 46 & 85 & & $2014[6]$ \\
\hline IBM-Chalmers $^{\mathrm{c}}$ & 850 & 50 & 90 & & $2015[5]$ \\
\hline \multicolumn{6}{|c|}{ Energy efficiency - VCSEL only } \\
\hline TU Berlin & 850 & 25 & RT & $56 \mathrm{fJ} / \mathrm{bit}$ & 2012 [9] \\
\hline Chalmers $^{\mathrm{a}}$ & 850 & 40 & RT & $73 \mathrm{fJ} / \mathrm{bit}$ & 2015 [11] \\
\hline Chalmers $^{\mathrm{a}}$ & 850 & 50 & RT & $95 \mathrm{fJ} / \mathrm{bit}$ & 2015 [11] \\
\hline TU Berlin & 980 & 35 & 85 & $139 \mathrm{fJ} / \mathrm{bit}$ & 2014 [12] \\
\hline TU Berlin & 980 & 38 & 85 & $177 \mathrm{fJ} / \mathrm{bit}$ & 2014 [13] \\
\hline \multicolumn{6}{|c|}{ Energy efficiency - full link } \\
\hline IBM-Sumitomo & 850 & 25 & RT & $1.0 \mathrm{pJ} / \mathrm{bit}$ & 2013 [10] \\
\hline IBM-Sumitomo & 850 & 35 & RT & $2.7 \mathrm{pJ} / \mathrm{bit}$ & 2013 [10] \\
\hline
\end{tabular}

${ }^{a}$ The VCSEL design presented in this paper. ${ }^{b}$ With a coherent VCSEL array. ${ }^{~}$ Using equalization.

$46 \mathrm{Gbit} / \mathrm{s}$ at $85^{\circ} \mathrm{C}$ has been demonstrated using $980 \mathrm{~nm}$ VCSELs with $23 \mathrm{GHz}$ bandwidth at high temperature [6]. Research exploring unconventional VCSEL structures, with coupled cavities for multiple resonance peaks, have demonstrated bandwidths up to $37 \mathrm{GHz}[7,8]$. So far only limited data transmission experiments have been presented using such devices [8].

In addition to high bit rates, the massive number of interconnects in data centers makes energy efficiency and low cost pressing issues. The energy efficiency of VCSELs is commonly quantified as the dissipated heat energy in the VCSEL per transmitted bit, denoted as the heat-to-data-ratio (HDR), and calculated as $H D R=\left(P_{\mathrm{el}}-P_{\mathrm{opt}}\right) / B R$, where $P_{\mathrm{el}}$ is the electrical DC power fed to the VCSEL, $P_{\text {opt }}$ is the optical output power, and $B R$ is the bit rate [9]. To make future systems feasible, the entire optical interconnect (laser driver, VCSEL,

johan.gustavsson@chalmers.se; emanuel.haglund@chalmers.se; anders.larsson@chalmers.se). Copyright (c) 2015 IEEE. Personal use of this material is permitted. However, permission to use this material for any other purposes must be obtained from the IEEE by sending a request to pubspermissions@ieee.org. 


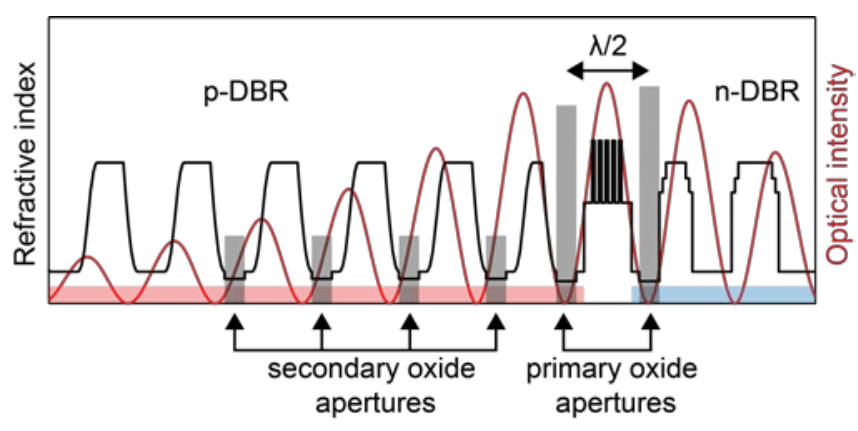

Fig. 1. Refractive index profile and simulated optical field intensity inside the VCSEL cavity. The position of the 30 -nm-thick primary $\mathrm{Al}_{0.98} \mathrm{Ga}_{0.02} \mathrm{As}$ and four secondary $\mathrm{Al}_{0.96} \mathrm{Ga}_{0.04} \mathrm{As}$ oxide apertures are indicated. The $p$ - and $n$-DBRs feature graded and step-index interfaces respectively.

photodetector, and receiver electronics) should consume at most $1 \mathrm{pJ} /$ bit even at high bit rates [1]. Previously, the energy consumption of the electronics have vastly exceeded that of the VCSEL, but energy-efficient circuits in 32-nm SOI CMOS have recently been demonstrated that make even the few $100 \mathrm{fJ} /$ bit dissipated by the VCSEL important. Researchers at IBM and Sumitomo have demonstrated a full 850-nm VCSELbased link at $25 \mathrm{Gbit} / \mathrm{s}$ with a total energy consumption of $1 \mathrm{pJ} / \mathrm{bit}$, of which the VCSEL dissipated 36\% (357 fJ/bit) [10]. Recent published results have demonstrated VCSELs dissipating less than $100 \mathrm{fJ} / \mathrm{bit}$ at 25 to $50 \mathrm{Gbit} / \mathrm{s}$ at RT $[9,11]$. However, at higher temperatures energy dissipation is still more than the twice the values at RT, as seen in Table I $[12,13]$.

Many of the advantages of VCSELs stem from the fact that their modal and active region volumes are small compared to edge emitting lasers. This enables VCSELs to reach high modulation bandwidths at low bias currents and low power consumption, making them ideal for the massive number of optical links in a data center or a supercomputer. In this paper we explore the limits of optical and electrical confinement by using the shortest possible cavity length and placing the current aperture as close as possible to the active region. High-speed data transmission using $980 \mathrm{~nm}$ VCSELs with similar confinement have previously been demonstrated $[6,14]$. We investigate the temperature dependent dynamic and static performance of our latest generation of high-speed oxideconfined 850-nm VCSELs with a focus on the impact of the short cavity and strong current confinement. These devices have recently demonstrated record-high small-signal modulation bandwidths of $30 \mathrm{GHz}$ at RT using a $3.5 \mu \mathrm{m}$ oxide aperture [11]. High bandwidths at low currents enabled data transmission at record energy efficiencies with HDRs of $73 \mathrm{fJ} / \mathrm{bit}$ at $40 \mathrm{Gbit} / \mathrm{s}$ and $95 \mathrm{fJ} / \mathrm{bit}$ at $50 \mathrm{Gbit} / \mathrm{s}$, using direct current modulation and on-off keying, in a back-to-back configuration.

The paper is organized as follows. Section II details the VCSEL design and fabrication. The static performance and effects of the strong carrier confinement are covered in Section III. The dynamic characteristics are presented and analyzed in Section IV, followed by a conclusion in Section V.

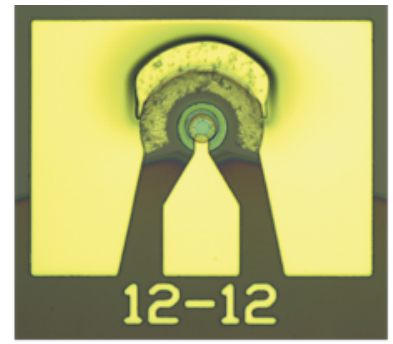

(a)

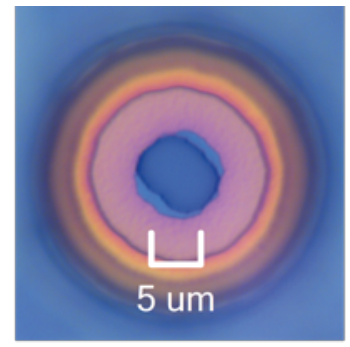

(b)

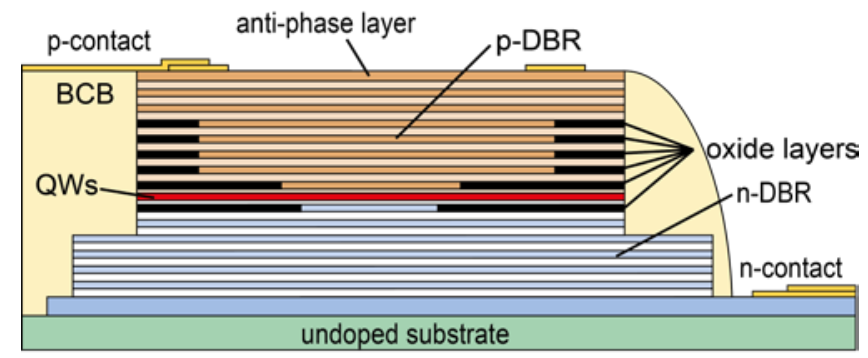

(c)

Fig. 2. (a) Microscope picture of fully processed high-speed VCSEL with high-frequency GSG-bondpads. (b) Etched mesa with visible upper (light blue) and lower (dark blue) oxide apertures showing different oxidation lengths. (c) Schematic cross-section of the VCSEL structure.

\section{DESIGN AND FABRICATION}

\section{A. Design}

The VCSEL design is a further development of our previous generation high-speed VCSELs [3, 4, 5, 15]. The VCSEL structure was grown by MOCVD at IQE Europe on a semiinsulating GaAs substrate. For high differential gain, the active region consists of five compressively strained 4-nm-thick $\mathrm{In}_{0.10} \mathrm{Ga}_{0.90}$ As quantum wells (QWs), separated by 6-nm-thick $\mathrm{Al}_{0.37} \mathrm{Ga}_{0.63} \mathrm{As}$ barriers. The photoluminescence peak (PL) is at $837 \mathrm{~nm}$, whereas the etalon wavelength is $849 \mathrm{~nm}$, giving a $-12 \mathrm{~nm}$ PL-to-etalon wavelength offset. The active region is positioned in a thin separate confinement heterostructure at the center of a half-wavelength $(\lambda / 2)$ thick cavity, see Fig. 1 . This means that the distance between the $p$ - and $n$-DBR is $\lambda / 2$, which is the shortest possible cavity length (the next possible cavity length is $3 \lambda / 2)$. The short cavity improves the longitudinal confinement factor $(\Gamma=0.033)$ and reduces the transport time across the intrinsic region compared to a $3 \lambda / 2$ cavity [15].

The top distributed Bragg reflector (DBR) is $p$-doped with carbon and features 21 pairs of mainly $\mathrm{Al}_{0.90} \mathrm{Ga}_{0.10} \mathrm{As} / \mathrm{Al}_{0.12} \mathrm{Ga}_{0.88} \mathrm{As}$ with graded interfaces and modulation doping optimized for low free-carrier absorption and low resistance. The top GaAs contact layer has an optical thickness of $\lambda / 2$ for an anti-phase reflection at the surface to enable post-fabrication tuning of the photon lifetime [16] as well as mode-filter integration [17]. The bottom $n$-doped DBR has 29 pairs with step-index interfaces and modulation doping with silicon. The first four pairs are $\mathrm{Al}_{0.90} \mathrm{Ga}_{0.10} \mathrm{As} / \mathrm{Al}_{0.12} \mathrm{Ga}_{0.88} \mathrm{As}$ to avoid oxidation of the bottom DBR during fabrication. The remaining 25 pairs are binary- 
ternary $\mathrm{AlAs} / \mathrm{Al}_{0.12} \mathrm{Ga}_{0.88} \mathrm{As}$, where $\mathrm{AlAs}$ is used to improve thermal conductivity, as compared to using an all ternary DBR.

Transverse optical and current confinement is provided by two primary oxide apertures formed by selective wet oxidation of 30-nm-thick $\mathrm{Al}_{0.98} \mathrm{Ga}_{0.02} \mathrm{As}$ layers. These are positioned as close to the QWs as possible; at the first nodes of the standing optical field on either side of the QWs, see Fig. 1. This design minimizes the lateral spreading of carriers in the intrinsic region and thereby promotes a high internal quantum efficiency. In our previous high-speed VCSEL generation we used a short $\lambda / 2$ cavity and oxide layers positioned further away from the QWs (at the second and third field nodes in the $p$-DBR). This lead to a relatively large current spreading under the oxide aperture, thereby preventing those carriers from contributing to the stimulated emission process, and resulted in larger threshold currents and lower internal quantum efficiency [15]. Relative to the previous design a large strain gradient is likely present in the short space between the compressively strained InGaAs QWs and the tensile strained oxide layers, see Fig. 1. Whether this compromises reliability remains to be investigated. Four 30-nm-thick $\mathrm{Al}_{0.96} \mathrm{Ga}_{0.04} \mathrm{As}$ layers form shallow, secondary oxide apertures which reduce the mesa capacitance $[16,18]$.

\section{B. Fabrication}

The VCSELs (Fig. 2) were fabricated using standard processing steps for oxide-confined GaAs-based VCSELs. First, Ti/Pt/Au top contact rings were evaporated on the highly doped $\left(5.5 \cdot 10^{19} \mathrm{~cm}^{-3}\right)$ p-type GaAs contact layer. VCSEL mesas with diameters of 22, 24, 26, and $28 \mu \mathrm{m}$ were dry etched by inductively coupled plasma (ICP) reactive ion etching (RIE) using a $\mathrm{SiCl}_{4} / \mathrm{Ar}$ gas mixture. An in-situ laser interferometer end-point system was used to precisely control the etch depth. This is necessary in order to expose the $\mathrm{Al}_{0.98} \mathrm{Ga}_{0.02}$ As layers without etching into the binary AlAs layers in the bottom DBR, which would oxidize rapidly if exposed during the oxidation process. Prior to oxidation $\mathrm{Si}_{x} \mathrm{~N}_{y}$ was deposited on the sample in order to prevent undesired oxidation of the mesa and chip surfaces. The $\mathrm{Si}_{x} \mathrm{~N}_{y}$ on the mesa sidewalls was removed using $\mathrm{NF}_{3}$ plasma etching and the oxide aperture was formed in a wet oxidation furnace at $420^{\circ} \mathrm{C}$. Different oxidation rates were observed on the $p$ - and $n$-side, resulting in two primary oxide apertures with slightly different size, see Fig. 2(b). In addition, an angular dependence of the oxidation rate was seen on the $n$ side, resulting in an elliptical oxide aperture. Non-circular oxide apertures have previously been reported in e.g. [19, 20]. The somewhat larger $p$-side oxide aperture was found to be circular. The oxide aperture diameter mentioned in this paper refers to the effective diameter of a circle with the same area as the smaller, elliptical aperture on the $n$-side. The $\mathrm{Al}_{0.90} \mathrm{Ga}_{0.10} \mathrm{As}$ layers surrounding the oxide layers oxidize vertically from the $\mathrm{Al}_{0.98} \mathrm{Ga}_{0.02} \mathrm{As}$ layer, increasing the oxide layer thickness from $\sim 30 \mathrm{~nm}$ to $\sim 50 \mathrm{~nm}$. This helps in further reducing mesa capacitance. After oxidation, a 50- $\mu \mathrm{m}$-diameter second mesa was dry etched through the bottom DBR down to the 1- $\mu \mathrm{m}$ thick GaAs $n$-contact layer. A Ni/Ge/Au $n$-contact was deposited using electron beam evaporation and annealed in a rapid thermal annealing system at $430^{\circ} \mathrm{C}$ for $30 \mathrm{~s}$ in an inert $\mathrm{N}_{2}$

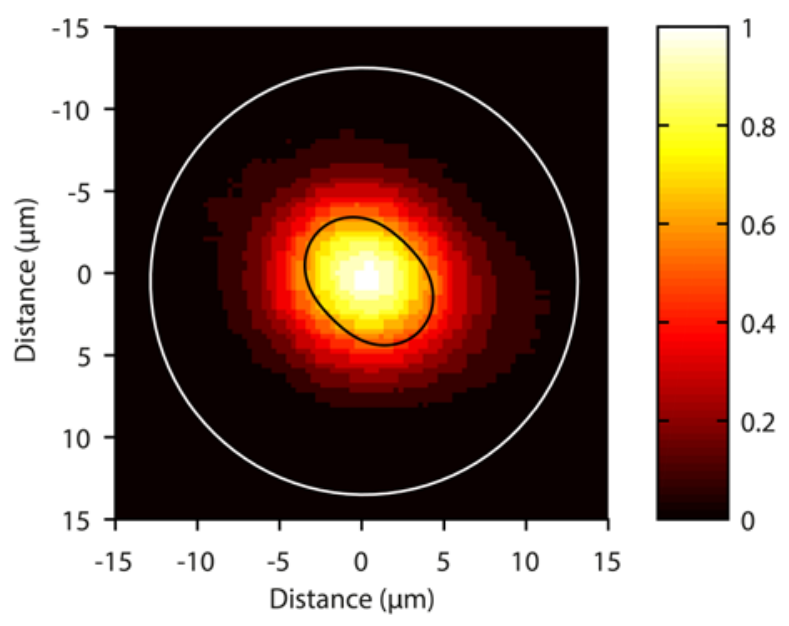

Fig. 3. Normalized intensity near-field image of a $7.5 \mu \mathrm{m}$ oxide aperture VCSEL biased at 0.75 times the threshold current. The VCSEL mesa is outlined in white and the approximate oxide aperture is shown in black.

atmosphere. After this the remaining contact layer underneath the signal bondpad was etched away using the ICP dry etch, exposing the semi-insulating GaAs substrate, in order to reduce the parasitic bondpad capacitance. Before planarization with a thick layer of benzocyclobutene (BCB), a layer of $\mathrm{Si}_{x} \mathrm{~N}_{y}$ was deposited to improve BCB adhesion. After hard cure, the BCB was patterned with photoresist and etched back to expose the top mesa and bottom contact using $\mathrm{CF}_{4} / \mathrm{O}_{2} \mathrm{ICP} / \mathrm{RIE}$ etching. To avoid burning of the resist during the BCB etch, the chip was attached to a sapphire carrier using thermally conductive cooling grease and the carrier backside was cooled by a Heflow during the etch. The cooling grease significantly improves the thermal conductivity between the chip and carrier and facilitates a high BCB etch rate and effortless resist removal. $\mathrm{Ti} / \mathrm{Au}$ bondpads in a ground-signal-ground (GSG) layout were sputtered onto the planarized VCSEL structure. As a final step, the chip was cleaved into four pieces for fine tuning of the photon lifetime by a shallow etch of the top DBR. This was done in order to optimize the top DBR reflectivity (top mirror transmission loss) for optimal bandwidth and output power [16]. A precise Ar-ion milling etch was used to etch 11, 20,37 , and $54 \mathrm{~nm}$ with an estimated accuracy of $\pm 1 \mathrm{~nm}$. To keep a good correlation between the simulated and experimental characteristics for extraction of internal parameters, it is essential to protect the mesa surface during fabrication to avoid unintentional etching or contamination with, for instance, resist residues. The mesa surface was protected by $\mathrm{Si}_{x} \mathrm{~N}_{y}$ during most of the processing steps and the chip was thoroughly cleaned during resist removal using standard solvents, $\mathrm{O}_{2}$ ashing and ozone cleaning.

\section{Static Performance}

The static performance was analyzed by measuring the current-power-voltage (IPV) using a large-area calibrated silicon photodetector with the VCSELs on a temperaturecontrolled heat-sink. The VCSELs with a surface etch depth of $20 \mathrm{~nm}$ were chosen for a more detailed study as they had the highest bandwidth at room temperature (see Section IV). When 


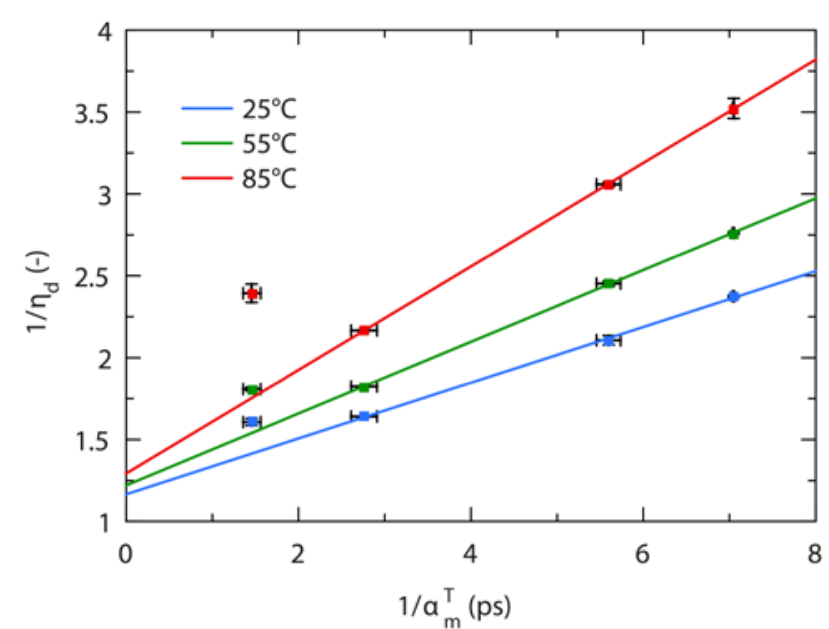

Fig. 4. The inverse of the differential quantum efficiency vs. the inverse of the top mirror loss rate with linear fits to extract internal quantum efficiency and optical loss for $7.5 \mu \mathrm{m}$ aperture VCSELs. Several devices were measured at each point, shown by standard deviation vertical error-bars. Horizontal errorbars represent an uncertainty in etch depth of $\pm 1 \mathrm{~nm}$.

VCSEL with other etch depths are discussed, this will be explicitly stated.

\section{A. Effects of Strong Carrier Confinement}

The strong transverse confinement of charge carriers was investigated by near-field imaging of the VCSEL below threshold. By measuring the spontaneous emission below threshold using a microscope with a CCD camera, the transverse carrier distribution in the QWs can be indirectly observed. As seen in Fig. 3, the spontaneous emission is well confined within the oxide aperture. The spontaneous emission profile closely resembles a Gaussian with a full-width-at-halfmaximum at the oxide aperture edge, albeit with an elliptic perturbation caused by the oxide aperture. The tight confinement leads to a carrier distribution with a good overlap with the optical mode, increasing the stimulated recombination efficiency. This is in contrast to our previous generation shortcavity VCSELs with oxide layers positioned further away from the QWs, where a significant lateral leakage current was observed [15].

The static characteristics of VCSELs with four different surface etch depths (i.e. four top mirror reflectivities) were measured in order to extract the internal optical loss $\alpha_{i}$ and internal quantum efficiency $\eta_{i}$ from the slope efficiency $S E$. First, the differential quantum efficiency was calculated as $\eta_{d}=q \lambda /(h c) \cdot S E$, with the elementary charge $q$, Planck's constant $h$, and speed of light $c$. The measured differential quantum efficiency $\eta_{d}$ can be related to the cavity losses as

$$
\frac{1}{\eta_{d}}=\frac{1}{\eta_{i}}\left(1+\left(\alpha_{i}+\alpha_{m}^{B}\right) \frac{1}{\alpha_{m}^{T}}\right)
$$

where $\alpha_{m}^{T}$ and $\alpha_{m}^{B}$ are the top and bottom mirror transmission loss rates. Using a 1-dimensional effective-index model to calculate $\alpha_{m}^{T}$ and $\alpha_{m}^{B}$ [21], the internal optical loss and internal quantum efficiency can be extracted from a linear fit of (1) as seen in Fig. 4. The devices etched only $11 \mathrm{~nm}$ (the leftmost points in Fig. 4) were omitted from the fit since the high cavity losses associated with the anti-phase layer results in a large threshold carrier density, which in turn leads to excessive carrier leakage from the QWs and reduced $\eta_{i}$. Values from the fits are shown in Table II. The high internal quantum efficiency of $86 \%$ at room temperature for a $7.5 \mu \mathrm{m}$ oxide aperture VCSEL indicates that the close proximity of the oxide layers to the QWs effectively confines the carriers to the active region. This is a significant improvement compared to the 65 to $70 \%$
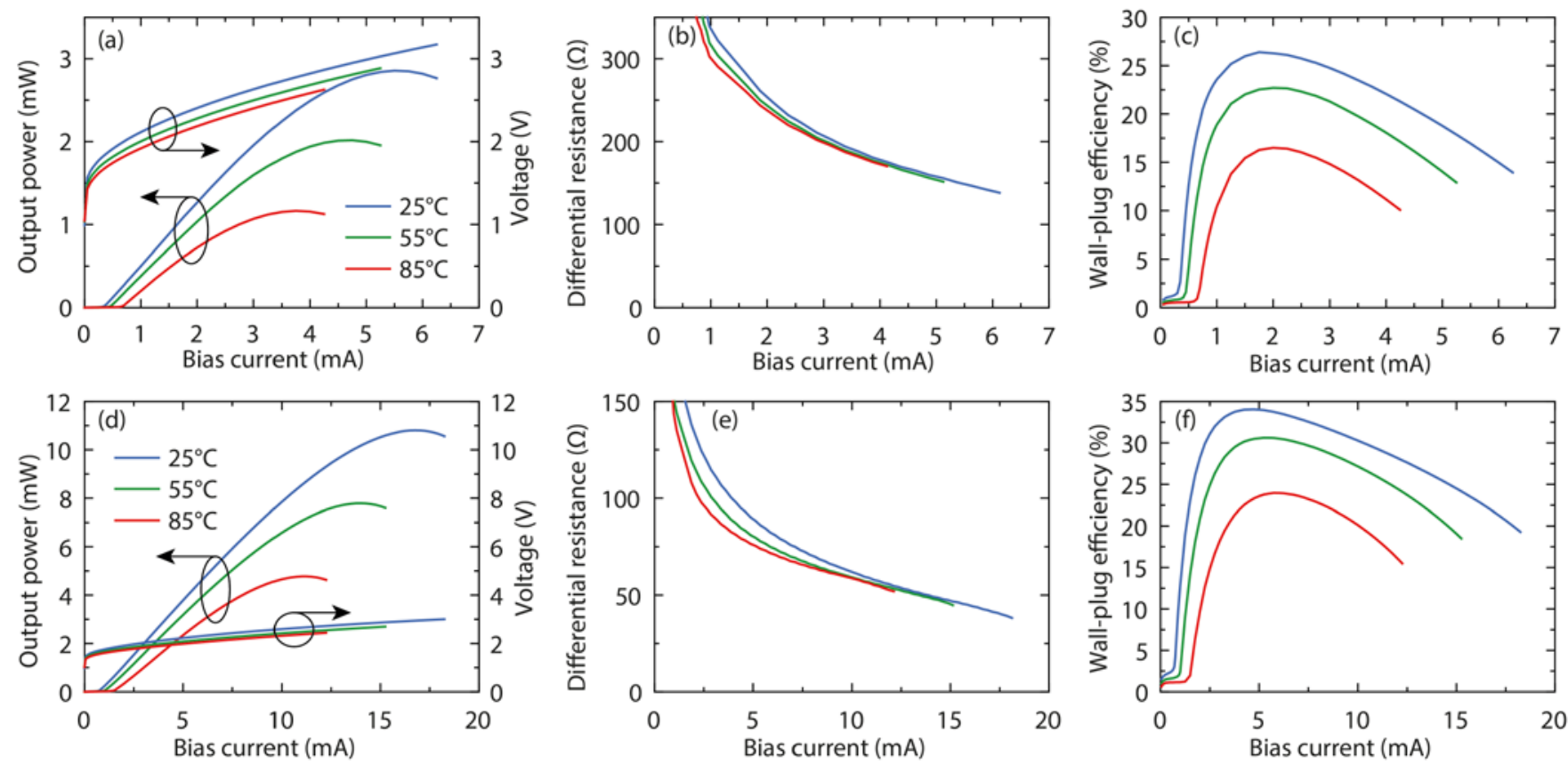

Fig. 5. Temperature dependent static characteristics as a function of bias current for a 3.5 (a)-(c) and a $7.5 \mu \mathrm{m}$ (d)-(f) oxide aperture VCSELs. Left: output power and voltage. Middle: differential resistance. Right: wall-plug efficiency. 
TABLE II

STATIC CHARACTERISTICS FOR DIFFERENT OXIDE APERTURES AND AMBIENT TEMPERATURES

\begin{tabular}{|c|c|c|c|c|c|c|c|c|c|}
\hline & \multicolumn{3}{|c|}{$3.5 \mu \mathrm{m}$} & \multicolumn{3}{|c|}{$5.5 \mu \mathrm{m}$} & \multicolumn{3}{|c|}{$7.5 \mu \mathrm{m}$} \\
\hline & $25^{\circ} \mathrm{C}$ & $55^{\circ} \mathrm{C}$ & $85^{\circ} \mathrm{C}$ & $25^{\circ} \mathrm{C}$ & $55^{\circ} \mathrm{C}$ & $85^{\circ} \mathrm{C}$ & $25^{\circ} \mathrm{C}$ & $55^{\circ} \mathrm{C}$ & $85^{\circ} \mathrm{C}$ \\
\hline Threshold current (mA) & 0.34 & 0.45 & 0.65 & 0.50 & 0.65 & 0.93 & 0.78 & 1.05 & 1.52 \\
\hline Max. output power (mW) & 2.9 & 2.0 & 1.2 & 7.0 & 5.2 & 3.3 & 10.8 & 7.8 & 4.8 \\
\hline Roll-over current (mA) & 5.5 & 4.8 & 3.8 & 11.5 & 9.8 & 8.0 & 16.8 & 14.0 & 11.3 \\
\hline Differential resistance $^{\mathrm{a}}(\Omega)$ & 178 & 216 & 244 & 80 & 97 & 108 & 55 & 66 & 73 \\
\hline Internal quantum efficiency (\%) & 81 & 84 & 80 & 81 & 77 & 72 & 86 & 82 & 77 \\
\hline \multirow[t]{2}{*}{ Internal optical loss ${ }^{\mathrm{b}}\left(\mathrm{ps}^{-1} / \mathrm{cm}^{-1}\right)$} & 0.22 & 0.32 & 0.44 & 0.12 & 0.16 & 0.22 & 0.13 & 0.17 & 0.23 \\
\hline & 27 & 40 & 55 & 16 & 20 & 28 & 17 & 21 & 29 \\
\hline Photon lifetime (ps) & 1.7 & 1.4 & 1.2 & 2.0 & 1.9 & 1.7 & 2.0 & 1.8 & 1.6 \\
\hline
\end{tabular}

${ }^{\mathrm{a}}$ Measured at half roll-over current / at roll-over current. ${ }^{\mathrm{b}}$ Converted from $\mathrm{ps}^{-1}$ to $\mathrm{cm}^{-1}$ assuming a group velocity of $8.0 \cdot 10^{9} \mathrm{~cm}^{\mathrm{s}}$.

estimated for our previous VCSEL design [15]. It should be noted that the linear fit assumes $\eta_{i}$ and $\alpha_{i}$ to be constant with respect to etch depth (photon lifetime). In reality, the 68-nmthick highly-doped GaAs contact layer will contribute to excess absorption loss through inter-band absorption for the VCSELs with a small etch depth (thick GaAs layer), resulting in an underestimation of $\eta_{i}$. However, inter-band absorption close to the bandgap is difficult to model. By using only the two rightmost data points in Fig. 4 for the fits (where most of the GaAs contact layer is etched away), this effect can be minimized, resulting in an $\eta_{i}$ as high as $94 \%$ at RT (using six VCSELs for each point to reduce measurement uncertainty). Therefore, the $\eta_{i}$ listed in Table II should be regarded as conservative estimates as the real values are likely higher.

The extracted internal optical loss was found to be similar for the 5.5 and $7.5 \mu \mathrm{m}$ aperture VCSELs, at 0.12 and $0.13 \mathrm{ps}^{-1}$ at RT. This is only slightly higher than the $0.11 \mathrm{ps}^{-1}$ calculated from the 1D simulation. The model only includes free-carrier absorption, but diffraction loss does not seem significant for the 5.5 and $7.5 \mu \mathrm{m}$ devices, since they have very similar losses. As expected, the $3.5 \mu \mathrm{m}$ VCSELs experience higher losses which we attribute to increased diffraction loss from the small oxide aperture. The extracted $\eta_{i}$ and $\alpha_{i}$ for the $3.5 \mu \mathrm{m}$ VCSELs should be regarded as rough estimates, since a small variation in the oxide aperture diameter on the order of $\sim 0.1 \mu \mathrm{m}$, makes the fit unreliable for small-aperture VCSELs. For the larger devices, the relative variation in oxide aperture area is much smaller, making the fits more reliable. The internal optical loss is approximately doubled from RT to $85^{\circ} \mathrm{C}$ due to larger freecarrier absorption coefficient at higher temperatures. Similar results have previously been reported in [16], and is connected with increased phonon scattering rates resulting in shorter carrier relaxation times. Using the extracted $\alpha_{i}$, the photon lifetime $\tau_{p}$ in Table II was calculated as $\tau_{p}=\left(\alpha_{i}+\alpha_{m}^{B}+\right.$ $\left.\alpha_{m}^{T}\right)^{-1}$. By assuming a group velocity of $8.0 \cdot 10^{9} \mathrm{~cm} / \mathrm{s}$, the loss rates can be converted to loss per unit length, see Table II.

\section{B. Static Characteristics}

IPV measurements for typical 3.5 and $7.5 \mu \mathrm{m}$ oxide aperture VCSELs can be seen in Fig. 5, and figures-of-merit for three oxide aperture sizes (3.5, 5.5, and $7.5 \mu \mathrm{m})$ are summarized in Table II. The strong confinement of carriers yields low threshold currents at room temperature of $0.34 \mathrm{~mA}$ for the $3.5 \mu \mathrm{m}\left(3.5 \mathrm{kA} / \mathrm{cm}^{2}\right)$ and $0.78 \mathrm{~mA}$ for the $7.5 \mu \mathrm{m}$ VCSELs $\left(1.8 \mathrm{kA} / \mathrm{cm}^{2}\right)$. It should be noted that even lower threshold currents are obtained for VCSELs with a larger part of the antiphase layer removed (i.e. higher top DBR reflectivity). Etching away the full anti-phase layer gives around 35\% lower threshold currents with $0.23 \mathrm{~mA}$ for a $3.5 \mu \mathrm{m}$ oxide aperture $\left(2.4 \mathrm{kA} / \mathrm{cm}^{2}\right)$ and $0.50 \mathrm{~mA}$ for a $7.5 \mu \mathrm{m}$ aperture $\left(1.1 \mathrm{kA} / \mathrm{cm}^{2}\right)$. At higher temperatures, the threshold current increases due to increased absorption, reduced internal efficiency, and an increase of the gain-wavelength detuning (lower gain), and is close to twice the RT value at $85^{\circ} \mathrm{C}$. The minimum threshold current was measured to be at between 0 and $5^{\circ} \mathrm{C}$, indicating that we have a positive gain-wavelength detuning above this point. This is disadvantageous for high-temperature static characteristics since the VCSEL needs to be pumped harder to reach threshold gain than for a negative gain-mode detuning [22]. It may, however, be beneficial for the dynamics, especially at room temperature, since this means operating the VCSEL at the short-wavelength side of the gain peak, where the differential gain is higher [23, 24].

High efficiency due to the strong confinement of carriers contributes to high slope efficiencies for the 5.5 and $7.5 \mu \mathrm{m}$ VCSELs, exceeding $0.86 \mathrm{~W} / \mathrm{A}$ at RT. The smaller $3.5 \mu \mathrm{m}$ device has a lower slope efficiency because of the increased internal losses. Even with the tight confinement of carriers, the differential resistance is only $\sim 50 \Omega$ for the $7.5 \mu \mathrm{m}$ and $\sim 160 \Omega$ for the $3.5 \mu \mathrm{m}$ aperture device, see Fig. 5(b) and (e). A low differential resistance is beneficial for both the static characteristics, since it reduces resistive heating, and for the dynamic characteristics as an impedance close to the standard $50 \Omega$ impedance minimizes unwanted microwave reflections, without the need for a customized broadband matching network. The differential resistance is about $30 \%$ lower than our previous generation of high-speed VCSELs which use the same DBR designs [15]. This may partly be explained by somewhat higher doping levels than intended, which is consistent with the larger than expected absorption losses.

High internal quantum efficiency, large slope efficiency, low threshold currents, and low differential resistance translates into high output power at low power consumption. This is also seen in the high wall-plug efficiencies (WPE) in Fig. 5(c) and (f). 

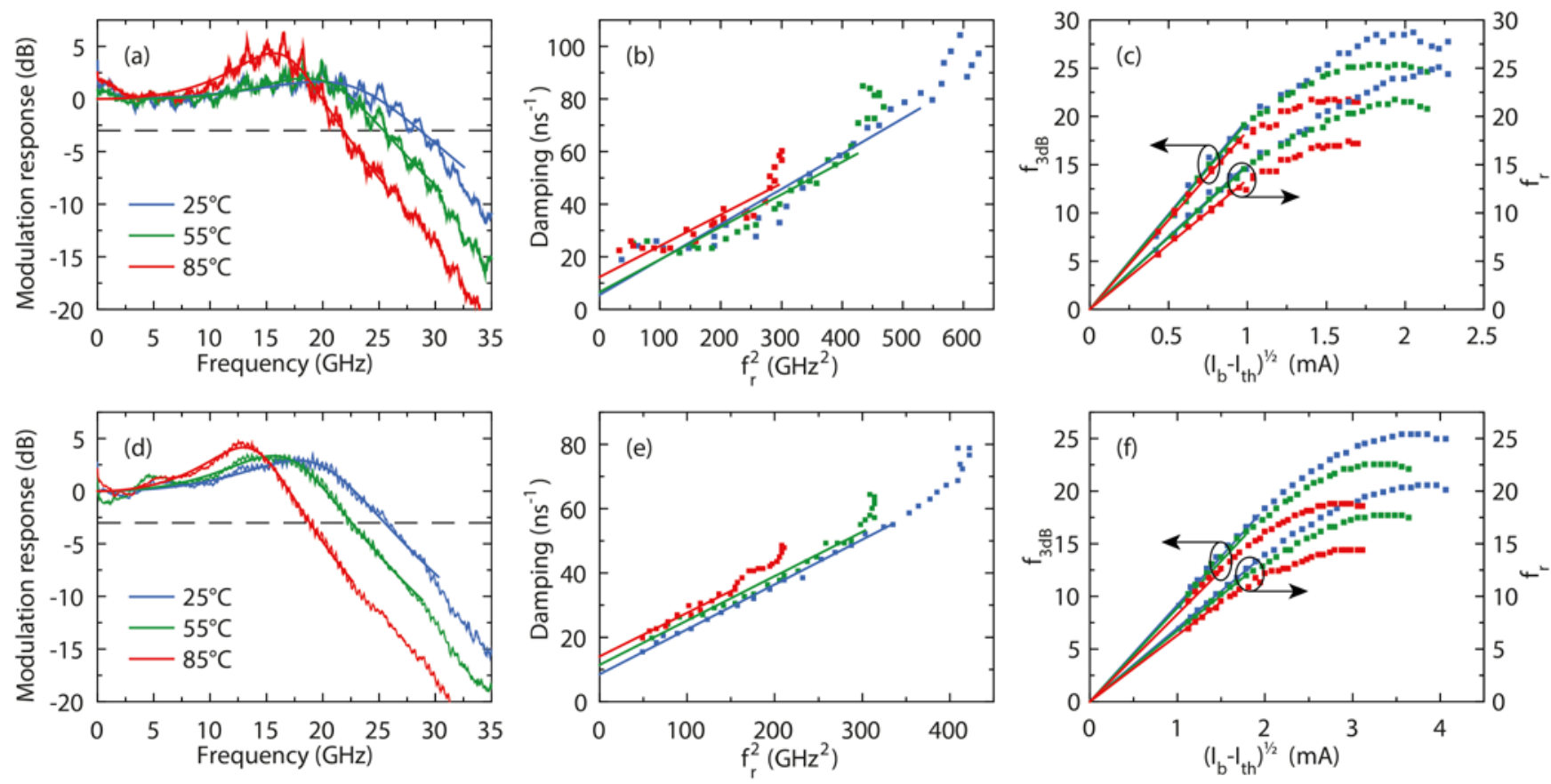

Fig. 6. Temperature dependent dynamic characteristics for a 3.5 (a)-(c) and a $7.5 \mu \mathrm{m}$ (d)-(f) oxide aperture VCSELs. Left: Small-signal modulation response at maximum bandwidth. Middle: Damping rate vs. resonance frequency squared with linear $K$-factor fits. Right: 3 -dB bandwidth and resonance frequency vs. square root of bias current above threshold with linear $D$-factor and MCEF fits.

For the $7.5 \mu \mathrm{m}$ VCSEL, the WPE peaks at $34 \%$ at $5 \mathrm{~mA}$ and exceeds $32 \%$ up to half the roll-over current. The smaller $3.5 \mu \mathrm{m}$ device WPE peaks at $26 \%$ at $2 \mathrm{~mA}$. For energy-efficient data transmission, the VCSELs should be biased at as low current as possible, preferably below half the roll-over current, where these devices show high efficiencies. Placing an oxide layer below the active region was not found to have a significant negative impact on the heat extraction from the active region. A thermal resistance of $2.3 \mathrm{~K} / \mathrm{mW}$ was measured at RT for the $7.5 \mu \mathrm{m}$ VCSEL, which is about $10 \%$ higher than our previous generation VCSELs with oxide layers only above the active region [5].

\section{DYNAMIC CHARACTERISTICS}

\section{A. Theory}

The dynamics of the resonant photon-carrier interaction in VCSELs is investigated by a small-signal modulation analysis. The small-signal modulation response $\left(\mathrm{S}_{21}\right)$ can be modelled as a second order damped system described by a resonance frequency $f_{r}$ and a damping rate $\gamma$ [25]. The VCSEL parasitics are included by adding an extra pole with a cut-off frequency $f_{p}$, giving the full three-pole transfer function

$$
H(f)=\text { const } \cdot \frac{f_{r}^{2}}{f_{r}^{2}-f^{2}+j(f / 2 \pi) \gamma} \cdot \frac{1}{1+j\left(f / f_{p}\right)}
$$

where $f$ is the modulation frequency. The parasitic transfer function may also be determined by $S_{11}$ measurements, which also allow fitting values of the parasitic elements to an equivalent circuit model [18]. Intrinsically, the VCSEL bandwidth is damping limited, with the damping increasing linearly with the square of the resonance frequency multiplied by the $K$-factor as

$$
\gamma=K f_{r}^{2}+\gamma_{0}
$$

where the offset $\gamma_{0}$ is approximately equal to the inverse differential carrier lifetime [25], and the $K$-factor can be related to internal VCSEL parameters by

$$
K=4 \pi^{2}\left(\tau_{p}+\frac{\varepsilon \chi}{v_{g}(\delta g / \delta n)}\right)
$$

where $\varepsilon$ is the gain compression, $\chi$ the transport factor, $v_{g}$ the group velocity of light, and $\delta g / \delta n$ the differential gain. The resonance frequency increases linearly with the square root of bias current above threshold according to

$$
f_{r}=D \sqrt{I_{b}-I_{t h}} .
$$

VCSELs with a large $D$-factor and low threshold current reach high resonance frequencies at low bias currents, which enables energy-efficient high-speed modulation. A large $D$-factor is also important in order to reach a high maximal VCSEL bandwidth, equivalent to reaching a large resonance frequency before current induced self-heating and thermal saturation deteriorates performance. The $D$-factor can be related to basic internal VCSEL parameters as

$$
D=\frac{1}{2 \pi} \sqrt{\frac{\eta_{i} \Gamma v_{g}}{q V_{a}} \cdot \frac{\delta g / \delta n}{\chi}}
$$

where $\Gamma$ is the optical confinement factor, $V_{a}$ the active region volume, and $\chi$ the transport factor. Equation (6) clearly shows that the small VCSEL active region volume contributes to high resonance frequencies at low bias currents. It is also obvious 
TABLE III

DYNAMIC CHARACTERISTICS FOR DIFFERENT OXIDE APERTURES AND AMBIENT TEMPERATURES

\begin{tabular}{|c|c|c|c|c|c|c|c|c|c|}
\hline & \multicolumn{3}{|c|}{ 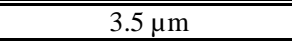 } & \multicolumn{3}{|c|}{ 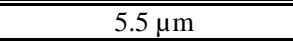 } & \multicolumn{3}{|c|}{ 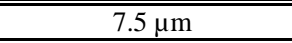 } \\
\hline & $25^{\circ} \mathrm{C}$ & $255^{\circ} \mathrm{C}$ & $85^{\circ} \mathrm{C}$ & $25^{\circ} \mathrm{C}$ & $\overline{55^{\circ} \mathrm{C}}$ & $85^{\circ} \mathrm{C}$ & $25^{\circ} \mathrm{C}$ & $255^{\circ} \mathrm{C}$ & $85^{\circ} \mathrm{C}$ \\
\hline$K$-factor (ns) & 0.13 & 0.12 & 0.12 & 0.14 & 0.13 & 0.12 & 0.14 & 0.13 & 0.14 \\
\hline Damping offset $\left(\mathrm{ns}^{-1}\right)$ & 5.5 & 6.6 & 12.3 & 7.3 & 9.1 & 14.9 & 8.5 & 12.4 & 14.1 \\
\hline Differential carrier lifetime (ps) & 180 & 150 & 80 & 140 & 110 & 70 & 120 & 80 & 70 \\
\hline $\operatorname{MCEF}\left(\mathrm{GHz} / \mathrm{mA}^{1 / 2}\right)$ & 19.6 & 19.4 & 18.4 & 12.7 & 12.5 & 11.7 & 9.2 & 8.9 & 8.3 \\
\hline$D$-factor $\left(\mathrm{GHz} / \mathrm{mA}^{1 / 2}\right)$ & 15.0 & 14.8 & 13.4 & 9.8 & 9.6 & 8.9 & 7.0 & 6.8 & 6.3 \\
\hline Max. modulation BW (GHz) & 29 & 26 & 22 & 27 & 24 & 22 & 26 & 23 & 19 \\
\hline Parasitic pole (GHz) & 20 & 17 & 17 & 19 & 18 & 21 & 20 & 18 & 19 \\
\hline Max. intrinsic BW (GHz) & 63 & 74 & 81 & 63 & 68 & 74 & 63 & 68 & 63 \\
\hline Max. thermal BW (GHz) & 39 & 33 & 27 & 36 & 32 & 26 & 32 & 27 & 22 \\
\hline
\end{tabular}

from (6) that strong optical confinement from the short $\lambda / 2$ cavity is advantageous. Analogous to the $D$-factor, the modulation current efficiency factor (MCEF) describes the increase of the small-signal modulation bandwidth with bias current as

$$
f_{3 d B}=\operatorname{MCEF} \sqrt{I_{b}-I_{t h}} .
$$

\section{B. Measurements and Analysis}

The temperature dependent dynamic performance was evaluated by $\mathrm{S}_{21}$-measurements at different heat-sink temperatures using a $67 \mathrm{GHz}$ Agilent E8361A network analyzer. The VCSELs were probed on-chip with a $40 \mathrm{GHz}$ Picoprobe 40A GSG high-frequency probe. The output light was collected by an AR-coated lens package and focused into a short multimode OM4 fiber connected to a $25 \mathrm{GHz}$ New Focus 1481-S-50 photodetector. The measured VCSEL response was corrected for probe insertion loss and frequency response of the detector. $\mathrm{S}_{21}$-measurements with fits of (2) for the 3.5 and $7.5 \mu \mathrm{m}$ VCSELs can be seen in Fig. 6, and dynamic performance parameters are listed in Table III. The ripples in the $\mathrm{S}_{21}$-measurement for the $3.5 \mu \mathrm{m}$ oxide aperture VCSEL are attributed to reflections in the measurement setup.

$K$-factors were extracted from linear fits of (3) as seen in Fig. 6(b) and (e), and were found to be relatively temperature insensitive at $0.11-0.14 \mathrm{~ns}$ for the three VCSELs at 25 to $85^{\circ} \mathrm{C}$. Small oxide aperture VCSELs have smaller photon lifetimes, but not significantly smaller $K$-factors. The reason is likely a lower differential gain due to the higher threshold carrier density, as has previously been reported [16]. The intrinsic VCSEL bandwidth can be roughly estimated as $f_{3 \mathrm{~dB}}^{\text {intrinsic }} \approx$ $2 \pi \sqrt{2} / K$, yielding intrinsic bandwidths exceeding $60 \mathrm{GHz}$ for all VCSELs at all temperatures [25]. This is far above the obtainable small-signal modulation bandwidths, as the VCSEL modulation speed is limited by thermal and parasitic effects. Low damping is, however, crucial to reach high modulation bandwidths since the resonance peak in the intrinsic response helps lifting the total VCSEL small-signal response [16]. However, a too small damping may result in excessive ringing and timing jitter for various bit rates [26]. The VCSEL damping was adjusted for maximum small-signal modulation bandwidth by adjusting the photon lifetime via a shallow surface etch as previously described.

The high optical confinement factor and the high internal quantum efficiencies contribute to large $D$-factors, with up to
$15 \mathrm{GHz} / \mathrm{mA}^{1 / 2}$ for the $3.5 \mu \mathrm{m}$ VCSEL, see Fig. 6(c) and (f). Even higher $D$-factors were obtained for VCSELs with longer photon lifetimes (larger etch depth), with $D$-factors exceeding $19 \mathrm{GHz} / \mathrm{mA}^{1 / 2}$ at RT for $3.5 \mu \mathrm{m}$ VCSELs with an etch depth of $54 \mathrm{~nm}$ (close to in-phase top DBR reflection). This larger etch depth also gives reduced threshold current $(0.23 \mathrm{~mA})$, but has the drawbacks of lower maximum bandwidth $(25 \mathrm{GHz})$ due to excessive damping, and reduced maximum output power by almost $50 \%$ (to $\sim 1.4 \mathrm{~mW}$ ) due to lower out-coupling of light from the cavity associated with the higher mirror reflectivity (all values at RT). The $D$-factor is relatively temperature stable, dropping only $10 \%$ from 25 to $85^{\circ} \mathrm{C}$. By using the extracted $\eta_{i}$, $\Gamma=0.033$ from the simulations, $V_{a}$ equal to the total quantum well thickness $(5 \cdot 4 \mathrm{~nm})$ times the oxide aperture area, and assuming $\chi=1$ and $v_{g}=8.0 \cdot 10^{9} \mathrm{~cm} / \mathrm{s}$, the differential gain $\delta g / \delta n$ can be calculated from (6). The VCSELs have differential gains at RT of 12 to $13 \cdot 10^{16} \mathrm{~cm}^{2}$, decreasing about $10 \%$ up to $85^{\circ} \mathrm{C}$. Therefore, the reduction in $D$-factor with temperature can be attributed in equal parts to the reduction in differential gain and internal quantum efficiency. In addition to high $D$-factors, large MCEFs of almost $20 \mathrm{GHz} / \mathrm{mA}^{1 / 2}$ was measured for the $3.5 \mu \mathrm{m}$ VCSEL at RT, indicative of the large modulation bandwidths at low bias currents.

The thermal limit of the maximum modulation bandwidth originates from the thermal saturation of the resonance frequency, as seen in Fig. 6(c) and (f). An estimate of the thermally limited bandwidth can be calculated as $f_{3 \mathrm{~dB}}^{\text {thermal }} \approx$ $1.55 \cdot f_{r}^{\max }$ and are listed in Table III [25]. For the $7.5 \mu \mathrm{m}$ VCSEL, the thermal bandwidth is $32 \mathrm{GHz}$ at RT, $6 \mathrm{GHz}$ larger than the modulation bandwidth of $26 \mathrm{GHz}$, indicating that the maximum modulation bandwidth is not significantly limited by thermal effects at room temperature. At higher ambient temperatures, the thermal saturation of the resonance frequency sets in earlier and the thermally limited bandwidth is reduced to just a few $\mathrm{GHz}$ above the achievable maximum modulation bandwidths. This implies that thermal effects are a limiting factor for the maximum bandwidth at higher temperatures.

The parasitic pole $f_{p}$ fitted from (2) was measured as 17 to $21 \mathrm{GHz}$ for all three VCSELs and shows no significant temperature dependence. Even though VCSELs with smaller oxide aperture have smaller capacitance over the oxide layer, the smaller current aperture also translates into a larger resistance, in effect making the parasitic pole relatively independent on oxide aperture diameter [18]. The maximum 
bandwidth is mainly limited by parasitics at room temperature. At elevated temperatures, the maximum modulation bandwidth is limited by both parasitics and thermal effects. However, at lower bias currents, parasitics are the main limiting factor even at high temperatures. Hence, to further improve bandwidths at low bias currents, parasitics must be reduced.

\section{CONCLUSION}

To summarize, we have demonstrated a new generation of high-speed VCSELs with strong confinement of optical fields and carriers. The use of a short $\lambda / 2$ cavity improves the longitudinal confinement factor and the dynamic properties. By positioning oxide layers as close to the QWs as possible, the internal quantum efficiency is improved, facilitating low threshold currents, high wall-plug efficiency, and state-of-theart dynamics at low bias currents. At room temperature, the maximum bandwidth is mainly limited by parasitics, whereas at $85^{\circ} \mathrm{C}$ ambient temperature, thermal effects also become important. At low bias currents used for energy-efficient data transmission, thermal effects are less pronounced and the dynamic performance is mainly limited by parasitic effects. Nevertheless, large bandwidths are reached at low bias currents over 25 to $85^{\circ} \mathrm{C}$, with a record-high $30 \mathrm{GHz}$ bandwidth achieved at room temperature for certain devices [11].

\section{ACKNOWLEDGMENT}

The authors would like to gratefully acknowledge IQE Europe for the growth of the epitaxial material. This project was financially supported by the Swedish Foundation for Strategic Research and the Knut and Alice Wallenberg Foundation.

\section{REFERENCES}

[1] A. Benner, "Optical interconnect opportunities in supercomputers and high end computing," in Optical Fiber Communication Conference 2012, OSA Technical Digest, paper OTu2B.4, Los Angeles, CA., 2012.

[2] J. B. Héroux, T. Kise, M. Funabashi, T. Aoki, C. L. Schow, A. V. Rylyakov and S. Nakagawa, "Energy-efficient 1060-nm optical link operating up to $28 \mathrm{~Gb} / \mathrm{s}$," J. Lightw. Technol., vol. 33, no. 4, pp. 733740, Feb. 2015.

[3] P. Westbergh, E. P. Haglund, E. Haglund, R. Safaisini, J. S. Gustavsson and A. Larsson, "High-speed $850 \mathrm{~nm}$ VCSELs operating error free up to 57 Gbit/s," Electron. Lett., vol. 49, no. 16, pp. 1021-1023, Aug. 2013.

[4] D. M. Kuchta, A. V. Rylyakov, F. E. Doany, C. L. Schow, J. E. Proesel, C. W. Baks, P. Westbergh, J. S. Gustavsson and A. Larsson, "71-Gb/s NRZ modulated 850-nm VCSEL-based optical link," IEEE Photon. Technol. Lett., vol. 27, no. 6, pp. 577-580, March 2015.

[5] D. M. Kuchta, A. V. Rylyakov, C. L. Schow, J. E. Proesel, C. W. Baks, P. Westbergh, J. S. Gustavsson and A. Larsson, "A 50 Gb/s NRZ modulated $850 \mathrm{~nm}$ VCSEL transmitter operating error free to $90^{\circ} \mathrm{C}$," $J$. Lightwave Technol., vol. 33, no. 4, pp. 802-810, Feb. 2015.

[6] P. Moser, J. A. Lott, P. Wolf, G. Larisch, H. Li and D. Bimberg, "Errorfree $46 \mathrm{~Gb} / \mathrm{s}$ operation of oxide-confined $980 \mathrm{~nm}$ VCSELs at $85^{\circ} \mathrm{C}$," Electron. Lett., vol. 50, no. 19, pp. 1369-1371, Sept. 2014.

[7] S. T. M. Frysile, M. P. Tan, D. F. Siriani, M. T. Johnson and K. D. Choquette, "37-GHz modulation via resonance tuning in single-mode coherent vertical-cavity laser arrays," IEEE Photon. Technol. Lett., vol. 27, no. 4, pp. 415-418, Feb. 2015.

[8] H. Dalir and F. Koyama, "29 GHz directly modulated $980 \mathrm{~nm}$ verticalcavity surface-emitting lasers with bow-tie shape transverse coupled cavity," Appl. Phys. Lett., vol. 103, p. 091109, Aug. 2013.
[9] P. Moser, J. A. Lott, P. Wolf, G. Larsich, H. Li, N. N. Ledentsov and D. Bimberg, "56 fJ dissipated energy per bit of oxide-confined $850 \mathrm{~nm}$ VCSELs operating at $25 \mathrm{Gbit} / \mathrm{s}, "$ Electron. Lett., vol. 48, no. 20, pp. 1292-1294, Sept. 2012.

[10] J. Proesel, B. G. Lee, C. W. Baks and C. Schow, "35-Gb/s VCSELBased Optical Link using 32-nm SOI CMOS Circuits," in Optical Fiber Communication Conference/National Fiber Optic Engineers Conference 2013, OSA Technical Digest, paper OM2H.2, Los Angeles, CA., 2013.

[11] E. Haglund, P. Westbergh, J. S. Gustavsson, E. P. Haglund and A. Larsson, "30 GHz bandwidth $850 \mathrm{~nm}$ VCSEL with sub-100 fJ/bit energy dissipation at 25-50 Gbit/s," Electron. Lett., vol. 51, no. 14, pp. 1096-1098, July 2015.

[12] H. Li, P. Wolf, P. Moser, G. Larisch, J. A. Lott and D. Bimberg, "Temperature-stable 980-nm VCSELs for 35-Gb/s operation at $85^{\circ} \mathrm{C}$ with 139-fJ/bit dissipated heat," IEEE Photon. Technol. Lett., vol. 26, no. 23, pp. 2349-2352, Dec. 2014.

[13] H. Li, P. Wolf, P. Moser, G. Larisch, A. Mutig, J. A. Lott and D. Bimberg, "Energy-efficient and temperature-stable oxide-confined 980 $\mathrm{nm}$ VCSELs operating error-free at $38 \mathrm{Gbit} / \mathrm{s}$ at $85^{\circ} \mathrm{C}$," Electron. Lett., vol. 50, no. 2, pp. 103-105, Jan. 2014.

[14] A. Mutig, P. Moser, J. A. Lott, P. Wolf, W. Hofmann, N. N. Ledentsov and D. Bimberg, "High-speed $850 \mathrm{~nm}$ and $980 \mathrm{~nm}$ VCSELs for highperformance computing applications," in Asia Communication and Photonics Conference and Exhibition, Proc. of SPIE, vol. 8308, Shanghai, 2011.

[15] P. Westbergh, R. Safaisini, E. Haglund, J. S. Gustavsson, A. Larsson, M. Geen, R. Lawrence and A. Joel, "High-speed oxide confined 850$\mathrm{nm}$ VCSELs operating error-free at $40 \mathrm{~Gb} / \mathrm{s}$ up to $85^{\circ} \mathrm{C}$," IEEE Photon. Technol. Lett., vol. 25, no. 8, pp. 768-771, April 2013.

[16] P. Westbergh, J. S. Gustavsson, B. Kögel, Å. Haglund and A. Larsson, "Impact of photon lifetime on high-speed VCSEL performance," IEEE J. Sel. Top. Quantum Electron., vol. 17, no. 6, pp. 1603-1613, Nov./Dec. 2011.

[17] R. Safaisini, E. Haglund, P. Westbergh, J. S. Gustavsson and A. Larsson, "20 Gbit/s data transmission over $2 \mathrm{~km}$ multimode fibre using $850 \mathrm{~nm}$ mode filter VCSEL," Electron. Lett., vol. 50, no. 1, pp. 40-42, Jan. 2014

[18] Y. Ou, J. S. Gustavsson, P. Westbergh, Å. Haglund, A. Larsson and A. Joel, "Impedance characteristics and parasitic speed limitations of highspeed 850-nm VCSELs," IEEE Photon. Technol. Lett., vol. 21, no. 24, pp. 1840-1842, Dec. 2009.

[19] P. Debernardi, G. P. Bava, C. Degen, I. Fischer and W. Elsäßer, "Influence of Anisotropies on Transverse Modes in Oxide-Confined VCSELs," IEEE J. Quantum Electron., vol. 38, no. 1, pp. 73-84, Jan. 2002.

[20] K. D. Choquette, K. M. Geib, C. I. .. H. Ashby, R. D. Twesten, O. Blum, H. Q. Hou, D. M. Follstaedt, B. E. Hammons, D. Mathes and R. Hull, "Advances in Selective Wet Oxidation of AlGaAs Alloys," IEEE J. Sel. Top. Quantum Electron., vol. 3, no. 3, pp. 916-926, June 1997.

[21] G. R. Hadley, "Effective index model for vertical-cavity surfaceemitting lasers," Opt. Lett., vol. 20, no. 13, pp. 1483-1485, July 1995.

[22] D. B. Young, J. W. Scott, F. H. Peter, M. L. Majewski, B. J. Thiebeault, S. W. Corzine and L. A. Coldren, "Enhanced performance of offsetgain high-barrier vertical-cavity surface-emitting lasers," IEEE J. Quantum Electron., vol. 29, no. 6, pp. 2013-2022, June 1993.

[23] H. Li, P. Wolf, P. Moser, G. Larsich, A. Mutig, J. A. Lott and D. Bimberg, "Impact of the quantum well gain-to-cavity etalon wavelength offset on the high temperature performance of high bit rate 980-nm VCSELs," IEEE J. Quantum Electron., vol. 50, no. 8, pp. 613-621, Aug. 2014.

[24] H. Nishimoto, M. Yamaguchi, I. Mito and K. Kobayashi, "Highfrequency response for DFB LD due to a wavelength detuning effect," J. Lightwave Technol., vol. 5, no. 10, pp. 1399-1402, October 1987.

[25] L. A. Coldren and S. W. Corzine, "Dynamic effects," in Diode Lasers and Photonic Integrated Circuits, New York, NY: Wiley, 2014, pp. 185-261. 
[26] E. P. Haglund, P. Westbergh, J. S. Gustavsson and A. Larsson, "Impact of damping on high-speed large signal VCSEL dynamics," J. Ligthwave Technol., vol. 33, no. 4, pp. 795-801, Feb. 2015.

Erik Haglund (S’12) received his B.Sc. in 2007 and M.Sc. in 2010, both in Engineering Physics from Chalmers University of Technology, Göteborg, Sweden. His studies also included an exchange year at the Swiss Federal Institute of Technology Zurich (ETH) and masters' thesis work at the Walter Schottky Institute of the Technische Universität München. He is currently working towards his Ph.D. degree in Microtechnology and Nanoscience at the Photonics Laboratory, Department of Microtechnology and Nanoscience, Chalmers University of Technology. His main research interests are spectral and dynamic properties of high-speed vertical-cavity surface-emitting lasers for optical interconnects.

Petter Westbergh received his M.Sc. degree in Engineering Physics and his Ph.D. degree in Microtechnology and Nanoscience from Chalmers University of Technology, Göteborg, Sweden, in 2007 and 2011, respectively. His thesis focused on the design, fabrication, and characterization of high-speed $850 \mathrm{~nm}$ vertical-cavity surface-emitting lasers (VCSELs) intended for application in short-reach communication networks. Since 2011, he has continued his work on improving the performance of high-speed VCSELs with the Department of Microtechnology and Nanoscience at Chalmers University of Technology. He has authored or coauthored more than 80 scientific journal and conference papers focused on VCSELs and optical interconnects.

Johan S. Gustavsson received the M.Sc. degree in electrical engineering and the Ph.D. degree in photonics from the Chalmers University of Technology, Göteborg, Sweden, in 1998 and 2003, respectively. His main research topics were mode dynamics and noise in vertical-cavity surface-emitting lasers. Since 2003, he has been a Researcher at the Photonics Laboratory, Department of Microtechnology and Nanoscience, Chalmers University of Technology, with an Assistant Professor position 2004-2008, and an Associate Professor position since 2011. From September-October 2009, he was a Visiting Scientist at CNR Polytechnico, Turin, Italy. He has authored or coauthored more than 140 scientific journal and conference papers, and his research has been focused on semiconductor lasers for short to medium reach communication, and sensing applications. This has included surface relief techniques for mode and polarization control in VCSELs, 1.3- $\mu \mathrm{m}$ InGaAs VCSELs/GaInNAs ridge waveguide lasers for access networks, 2.3-3.5- $\mu \mathrm{m}$ GaSb VCSELs for $\mathrm{CO}, \mathrm{CO}_{2}$, and $\mathrm{NH}_{3}$ sensing, and tunable VCSELs via moveable mirror for reconfigurable optical interconnects. He is currently working on 56-Gb/s 850-nm VCSELs for next generation datacom links, blue/green GaN VCSELs, high contrast gratings as feedback elements in microcavity lasers, and heterogeneous integration of III/Vbased VCSEL material on Si-platform.

Emanuel P. Haglund (S'14) received the M.Sc. degree in engineering physics from Chalmers University of Technology, Göteborg, Sweden, in 2013, where he is currently working toward the Ph.D. degree in Microtechnology and Nanoscience at the Photonics Laboratory, Department of Microtechnology and Nanoscience. His current research interests include fabrication and characterization of high-speed vertical-cavity surface-emitting lasers for future optical interconnects in data centers and high-performance computers.

Anders Larsson (M'88-SM'09-F'14) received the M.Sc. and Ph.D. degrees in electrical engineering from Chalmers University of Technology, Göteborg, Sweden, in 1982 and 1987, respectively. In 1991, he joined the Faculty at Chalmers, where he was a Professor in 1994. From 1984 to 1985, he was with the Department of Applied Physics, California Institute of Technology, and from 1988 to 1991 with the Jet Propulsion Laboratory, both at Pasadena, CA, USA. He has been a Guest Professor at Ulm University, Germany, at the Optical Science Center, University of Arizona, Tucson, USA, at Osaka University, Japan, and at the Institute of Semiconductors, Chinese Academy of Sciences, China. His scientific background is in the areas of optoelectronic materials and devices for optical communication, information processing, and sensing. His research interests include vertical-cavity surface-emitting lasers and optical interconnects. He has published more than 500 scientific journal and conference papers and two book chapters. Prof. Larsson coorganized the IEEE Semiconductor Laser Workshop 2004, organized the European Semiconductor Laser Workshop 2004, was a Coprogram Chair for the European Conference on Optical Communication 2004, and was the Program and General Chair for the IEEE International Semiconductor Laser Conference in 2006 and 2008, respectively. He is a Member of the IEEE Photonics Society Board of Governors, an Associate Editor for JOURNAL OF LIGHTWAVE TECHNOLOGY and a Member of the Editorial Board of IET Optoelectronics. He is a Fellow of IEEE, OSA and EOS. In 2012, he received the HP Labs Research Innovation Award. 